\title{
Discussion: Rate effects during pipeline upheaval buckling in sand
}

\section{Mark Fraser Bransby}

Senior Principal Engineer, Advanced Geomechanics, Perth, Australia, formerly Senior Lecturer, Civil Engineering, University of Dundee, Scotland Jamie Ireland

JSI Engineering Consultants Ltd, Aberdeen, Scotland (formerly the University of Dundee)

\section{Contribution by Byrne, Schupp and Martin}

The authors, in their paper (Bransby and Ireland, 2009), have highlighted a very interesting issue in relation to buried pipeline response in saturated sand. As they identify, the response will depend on the relative density of the soil, and in the case of jettrenching it is highly likely that the backfill will come to rest at its minimum density. If the sand contains a significant fraction of fines, such that excess pore water pressures are able to develop, then there is a significant risk of liquefaction (whether wave induced or vibration induced) early in the pipeline's life. We draw attention here to some work recently carried out at Oxford University, funded by EPSRC and Technip, that demonstrates this possibility.

Pipeline uplift tests were conducted at a range of velocities in very loose saturated sand, exploring drained, partially drained and almost undrained loading conditions. The sand was Redhill 110, a uniformly graded silica sand with a $d_{50}$ of $0.12 \mathrm{~mm}$, and the pipe diameter was $100 \mathrm{~mm}$. The results show that the vertical slip model is appropriate for predicting the drained resistance. However, tests at higher velocities reveal a rate-dependent behaviour, and if the pipe is pulled fast enough a complete loss of resistance is possible (see Figure 14). At intermediate velocities there is initially a reduction in resistance due to the very large positive excess pore pressures. The soil then regains strength as these excess pore pressures dissipate, and eventually the load-displacement curve reverts to the drained response. Figure 15 highlights the results obtained at an intermediate velocity, showing the excess pore pressure measured on the surface of the pipe (at midheight) and the uplift force.

On the basis of these tests, we hypothesise that the initial movement of the pipe causes a total loss of effective stress (i.e. liquefaction), but that continued uplift does not cause any further excess pore pressures to develop (i.e. the soil collapses to the critical void ratio, and any further shearing occurs at constant volume). The dissipation with time of the original distribution of excess pore pressure can be approximated by Terzaghi's onedimensional equation with appropriate boundary conditions. The vertical slip model can therefore be adapted, making allowance

\section{Byron Byrne}

Lecturer, Department of Engineering Science, University of Oxford, UK Jens Schupp

Research student, Department of Engineering Science, University of Oxford, UK

\section{Chris Martin}

Lecturer, Department of Engineering Science, University of Oxford, UK

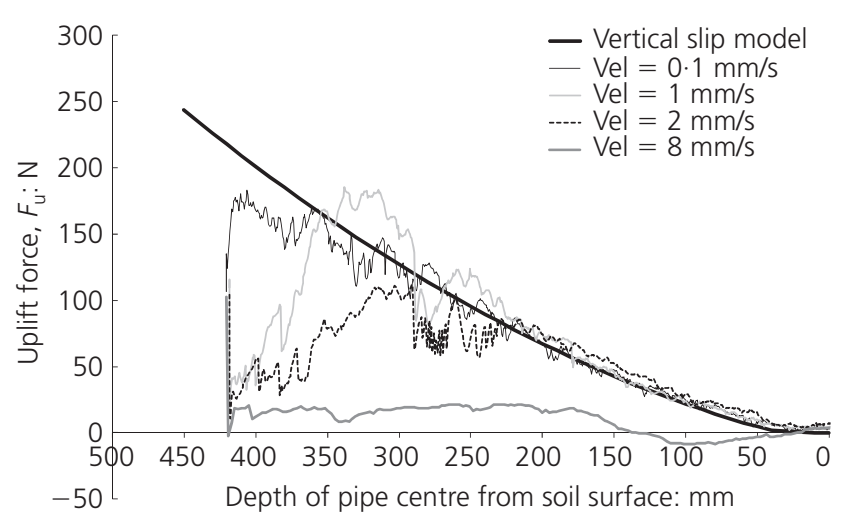

Figure 14. Response of pipes moving upward through saturated sand (data from Christofis, 2006)

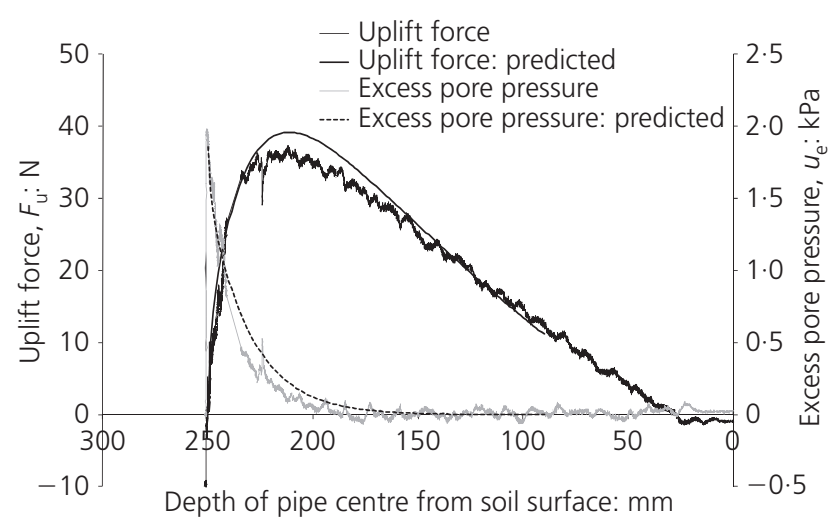

Figure 15. Results from an uplift test carried out at $1 \mathrm{~mm} / \mathrm{s}$ in saturated loose sand

for the distribution of pore pressure with depth and with time, giving typical results also shown in Figure 15.

Of course, the condition described here will be critical early in the pipeline's life. As time passes there will be small pipe vibrations and cyclic wave-induced vibrations that cause shakedown of the 
soil skeleton around the pipeline. Small increases in relative density may then lead to the situation described in the paper, where the uplift force at a given depth increases with the uplift velocity. Of course, as identified by the authors, care would need to be taken in assessing probable uplift velocities, and so the designer might well opt for no enhancement of the drained capacity.

\section{Authors' reply}

The authors are pleased that the paper has generated additional debate, and would like to thank the discussers for presenting their very interesting additional data and analysis, which have serious implications for the installation and design of jet-trenched pipelines.

A major point from the discussion and paper appears to be the importance of knowledge of the density of the granular backfill covering a buried offshore pipeline. If the backfill is very loose, its tendency to reduce volume during shearing will provoke positive excess pore pressures, which will reduce uplift resistance with increasing rate. Complete flow liquefaction will occur in the worst-case situation. Alternatively, if the backfill is denser, the tendency for dilation (volume increase during shearing) will provoke pore water suctions and increase uplift resistance for faster velocities. This leaves three questions.

(a) What is the critical relative density where this behaviour changes?

(b) What is the density of backfill offshore?

(c) What should the designer of the pipeline assume when performing design/stability calculations?

Further experimental work is required to answer the first question. However, the critical relative density depends on the average effective stress in the problem being investigated, because the volumetric change during shearing of soil is stress-level dependent (Bolton, 1986). Indeed, Bolton's (1986) relationships suggest that no dilation occurs when $I_{\mathrm{d}} \leqslant 1 /\left(10-\ln p^{\prime}\right)$, although the empirical relationship he proposed was not tested for very low effective stress. In full-scale, fully drained, uplift tests, $p^{\prime} \approx 5-13 \mathrm{kPa}$ at the base of the area of interest (typical depth of interest $\approx 1-2 \mathrm{~m}$; typical buoyant unit weight, $\gamma^{\prime} \approx 8-10 \mathrm{kN} / \mathrm{m}^{3}$; assumption of $K_{0}=0 \cdot 5$ ), implying that the critical relative density, $I_{\mathrm{d}} \approx 2 \cdot 0-$ $13 \cdot 5 \%$. In $1 / 10$ th-scale laboratory tests, the critical relative density is calculated as $9 \cdot 4-10 \cdot 3 \%$. The limited experimental evidence to date suggests that it falls between $0 \%$ (discussers' result, which reduces capacity with rate) and $13 \%$ (authors' result, which increases capacity with rate), agreeing with the above tentative analysis. Clearly, the critical density will depend on pipe diameter, cover depth and the soil type.

The next thing to consider is whether the backfill is likely to be looser or denser than the critical relative density (question (b)). As stated by the discussers, this is complicated by the fact that the backfill density generally increases with time after burial, owing to wave actions and in-service pipeline movements, in addition to initial (re-)consolidation of the backfill following placement. However, the initial relative density and soil fabric will depend largely on the pipeline installation method and the soil type. The two most prevalent burial methods offshore in soft soils are jettrenching and ploughing. In the former method, water is injected into the soil at high pressure, which is likely to fully fluidise granular soil to give a very low relative density (perhaps in the order of $0 \%$ ), as modelled by the discussers. Alternatively, during ploughing, a large plough share is pulled through the seabed to generate a triangular trench (e.g. Palmer et al., 1979) with spoil heaps on either side. The cover to the pipeline is generated by pushing the soil in the spoil heaps back into the trench on top of the pipeline with a backfill plough (Cathie et al., 1998). In this second case the relative density is quite uncertain, as the soil is first disturbed to form the spoil heaps, and then falls back down the trench (perhaps entraining water) when pushed by the backfill blade, Cathie et al. (2005) suggest a relative density of $10-30 \%$ as found during hydraulic filling (Stoutjesdijk et al., 1998), slightly denser than the critical voids ratio, and in the range of the experiment conducted by the authors. In conclusion, a jet-trenched pipeline is likely initially to be susceptible to reducing uplift capacity with rate (discussers' case), but a mechanically backfilled trench may be sufficiently dense to generate the type of response seen by the authors, although both are likely to become denser with time.

The consequence for the pipeline is subtle. Initially, it might be liable to flotation or snap-buckling if the pipe material is lightweight and installed by jetting, especially if service or flotation loads are applied soon after installation. In this case the designer should consider the reduction of uplift capacity with rate, as it may be critical to selection of embedment depth. However, if the pipeline is safe immediately after installation at the beginning of its design life, any 'in-service' improvement will ensure that the drained uplift resistance is likely to be conservative for use in calculations.

It is clear that further research is warranted, given the financial and environmental consequences of pipeline failure. Research could include investigation of backfill properties achieved in practice, and the effects of these on pipeline response along with associated mitigation measures.

\section{REFERENCES}

Bolton MD (1986) The strength and dilatancy of sands. Géotechnique 36(1): 65-78.

Bransby MF and Ireland J (2009) Rate effects during pipeline upheaval buckling in sand. Proceedings of the Institution of Civil Engineers - Geotechnical Engineering 162(5): 247256.

Cathie D, Barras S and Machin J (1998) Backfilling pipelines: state of the art. In Proceedings of the 21st Offshore Pipeline Technology Conference, Oslo. IBC UK Conferences, London, UK, pp. 1-29.

Cathie DN, Jaeck C, Ballard J-C and Wintgens JF (2005) Pipeline 
geotechnics: state-of-the-art. In Frontiers in Offshore Geotechnics: Proceedings of the 1st International Conference on Frontiers in Offshore Geotechnics (ISFOG 2005), Perth (Gourvenec S and Cassidy M (eds)). Taylor \& Francis, Abingdon, UK, pp. 95-114.

Christofis V (2006) An Investigation into the Upheaval Behaviour of Buried Offshore Pipelines. Fourth Year Project Report, Department of Engineering Science, University of Oxford, UK.

Palmer AC, Kenny JP, Perera MR and Reece AR (1979) Design and operation of an underwater pipeline trenching plough. Géotechnique 29(3): 305-322.

Schupp J, Byrne BW, Martin CM, Oliphant J, Maconochie A and Cathie DN (2008) Experimental modelling of the unburial behaviour of pipelines. Proceedings of the 40th Annual Offshore Technology Conference, Houston, TX, USA, paper no. 19573.

Stoutjesdijk TP, de Groot MB and Lindenberg J (1998) Flow slide prediction method: influence of slope geometry. Canadian Geotechnical Journal 35(1): 43-54. 